\title{
Patella kırıklarında tedavi yaklaşımları ve patellektominin tedavideki yeri
}

\author{
Treatment approaches in patella fractures and place of patellectomy \\ in treatment
}

\author{
Cahit Koçak, Ahmet Özgür Yıldırım
}

Sağlık Bilimleri Üniversitesi Ankara Numune Eğitim ve Araştırma Hastanesi, Ortopedi ve Travmatoloji Kliniği, Ankara

Patella insan vücudundaki en büyük sesamoid kemiktir ve patella kırıkları tüm kırıkların yaklaşık \%1'ini oluşturur. Dizin ekstansör mekanizmasında önemli görevleri olan bu kemiğin kırıklarında, aktif ekstansiyon mekanizması genellikle etkilenir. Tanıda genellikle fizik muayene ve direkt grafi yeterlidir. Tedavi kırık tipi ve morfolojisine göre değişmekle birlikte konservatif veya cerrahi tedavi tercihi yapılır. Cerrahi tedavide K-teli ve gergi bandı tekniği en yaygın kullanılan yöntemdir. Kısmi ya da total patellektomi öncelikli tedavi tercihi değildir. Patella kırıklarının tedavisinden sonra fonksiyonel bozulma yaygındır. Bu derlemede patella kırık çeşitleri tartışılmış ve güncel tedavi yöntemleri gözden geçirilmiştir.

Anahtar sözcükler: patella kırı̆̆; gergi bandı; patellektomi
Patella is the largest sesamoid bone in human body and patella fractures constitute about $1 \%$ of all fractures. Active extensor mechanism usually affected by fractures of this bone which have important roles in that mechanism. Physical exam and conventional radiography are usually enough for diagnosis. Conservative or surgical treatment is preferred according to fracture type and morphology. Most common techniques are K-wire and tension banding. Partial or total patellectomy shouldn't be preferred as a primary treatment technique. Functional impairment after treatment of patella fractures are common. In this article, types of patella fractures were discussed, and current treatment modalities reviewed.

Key words: patella fracture; tension banding; patellectomy nsan vücudundaki en büyük sesamoid kemik olan patella, dizin ekstansör bölümü içinde proksimalde rektus femoris, vastus medialis, intermedius ve lateralis kasları ile kuadriseps tendonu, distalde patellar tendon arasında bulunmaktadır. Patellanın en önemli görevleri, diz ekstansiyon kuvvetini arttırması ve diz eklemini direkt travmadan korumasıdır. ${ }^{[1]}$ Ayrıca patella vücuttaki en kalın kartilaj tabakaya sahip kemiktir. ${ }^{[2]}$

Patella kırıkları tüm kırıkların yaklaşık \%1'ini oluşturur. Yirmi ila elli yaş aralığında ve erkek cinsiyette daha sıktır. Yaralanma mekanizması direkt ya da indirekt travmadır ve olguların çoğunda dizin aktif ekstansiyon mekanizması kaybolur. ${ }^{[1]}$ Direkt mekanizma genellikle araç içi trafik kazasında fleksiyondaki dizin ön panele çarpması şeklindedir.

\section{TANI}

Öykü ve fizik muayenede, travma öyküsü ile birlikte şişlik, ağrı, hassasiyet, dizin aktif ekstansör güçsüzlüğü ya da yokluğu bulguları vardır. Palpasyonda kırığa ait defekt hissedilebilir. Diz üzerinde dermabrazyon veya açık kırığa ait yara bulunabilir (açık patella kırı̆̆ı ilk 6-8 saat içinde acil cerrahi tedavi gerektirir). Yüksek enerjili yaralanmalar sonucu görülen patella kırıklarında, eşlik edebilecek yaralanmalar açısından dikkatli olunmalı ve tüm vücut travma muayenesi yapılmalıdır.

Radyolojik değerlendirmede direkt grafiler genellikle tanı açısından yeterlidir. Dizin iki yönlü grafisi ve patella tanjansiyel grafi çekilmelidir. Anteroposterior (AP) incelemede patella orta hatta femoral sulkusun iz düşümünde olmalıdır. Lateral grafi; patellar tendon

- Illetişim adresi: Op. Dr. Cahit Koçak, Ülkü Mahallesi Talatpaşa Bulvarı No: 5 Altındağ, Ankara, Türkiye Tel: 0312 - 5085101 e-posta: cahitkocak@gmail.com

- Geliş tarihi: 1 Eylül 2018 Kabul tarihi: 1 Eylül 2018 
değerlendirmesi için tibial tüberkül dahil olacak şekilde çekilmelidir. Patella yüksekliği değerlendirmesinde Insall-Salvati metodu (lateral grafide patella uzunluğu ve patellar tendon uzunluklarının birbirlerine oranıdır, normal oran 1'dir, $<0,8$ ise patella alta [örn; patellar tendon yırtığı], >1 ise patella baja [örn; kuadriseps tendon yırtığı]) kullanılır. ${ }^{[1]}$

Tanıda bilgisayarlı tomografi (BT), stres kırıklarının değerlendirilmesinde sintigrafi, kartilaj yumuşak doku değerlendirilmesinde manyetik rezonans (MR) yardımcl tetkiklerdir.

Patellanın en sık görülen kemik gelişim anomalisi olan bipartit patella ayırıcı tanıda kırık ile karışabilir. Sıklıkla patellanın superolateral köşesinde yer alır, genellikle klinik bulgu vermeyen ve bilateral olan, grafide sklerotik kenarlı görülen bir durumdur. Saupe sınıflandırmasına göre inferior tip (\%5), lateral veya vertikal tip (\%20) ve superolateral tip (\%75) olmak üzere üç tiptir. ${ }^{[3,4]}$

\section{SINIFLANDIRMA}

Direkt ve künt travma ile genellikle çok parçalı kırık tipleri, indirekt travma ile genellikle transvers kırık tipi ve avulsiyon kırıkları görülür. Transvers ve avulsiyon kırıkları sıklıkla genç hastalarda görülür. Yaşı ya da osteoporotik hastalarda çok parçalı kırık tipi daha sıktır.

Sınıflama aşağıdaki şekillerdeki gibidir. Kırı̆̆ın geometrik şekli, deplasman miktarı ve yerleşimini tanımlayıcı sınıflama Şekil 1'de gösterilmiştir. AO (Arbeitsgemeinschaft für Osteosyntesefragen) sınıflamasına göre patella kırıkları üç tipe ayrılır (Şekil 2). Tip A (eklem dışı) kırıklar, avulsiyon kırıkları bu gruba girer.
Tip B kırıklar ekstansör mekanizmanın korunduğu, genellikle vertikal, kısmen eklemi ilgilendiren kırıklardır. Tip C kırıklar eklemi ilgilendiren ve ekstansör mekanizmanın tamamen bozulduğu kırıklardır.

\section{TEDAVi}
Patella Kırıklarında Tedavi Yöntemleri (Tablo 1)
Konservatif tedavi
Cerrahi tedavi
- Açık redüksiyon (AR) + gergi bandı tekniği
- AR + vida ile tespit
- Kombine sistemler (Vida + tel)
- Diğer tespit yöntemleri (plak ve vida tespiti, titanyum mesh)
- Parsiyel patellektomi
- Total patellektomi

Tedavide yüzey uyumunun sağlanması, eklem hareket açıklığının kazanılması ve ekstansör mekanizmanın fonksiyonel olması hedeflenir. ${ }^{[5]}$

Illk tanı anında geniş travmatik intra-artriküler hemartrozu bulunan hastalara eklem aspirasyonu ve fizik muayeneyi kolaylaştırmak için eklem içi lokal anestezi uygulanabilir. Akut tedavide öncelikle diz tam ekstansiyonda (hiperekstansiyon değil) olacak şekilde atel veya breys ile tespit edilir. Şişlik ve ağrıyı azaltmak için yatak istirahati, alt ekstremiteye elastik bandaj uygulaması, soğuk uygulama ve ekstremite elevasyonu uygulanır.

Konservatif tedavi; eklem bütünlüğü bozulmamış ve ekstansör mekanizma hasarı olmayan kırıklarda, 4-6

Tablo 1. AO/OTA kırık sınıflamasına göre kırık tipi ve morfolojisine göre tedavi algoritması

\begin{tabular}{|c|c|c|}
\hline Kırık tipi & Kırık morfolojisi & Tedavi \\
\hline 34-A & $\begin{array}{l}\text { - Ekstra-artriküler kırıklar } \\
\text { - Avulsiyon kırıkları }\end{array}$ & $\begin{array}{l}\text { - Cerrahi tedavi } \\
\text { - Vida+gergi bandı kombinasyonu } \\
\text { - Transosseöz sütür ile tendon onarımı }\end{array}$ \\
\hline 34-B & $\begin{array}{l}\text { - Parsiyel eklem içi kırıkları } \\
\text { - Vertikal kırıklar }\end{array}$ & $\begin{array}{l}\text { - Nondeplase (parçalar arası deplasman }<3 \mathrm{~mm} \text {, eklem içi deplasman }<2 \mathrm{~mm} \text { ve ekstansör } \\
\text { mekanizma hasarı yok) ise konservatif tedavi (sirküler alçı veya açı ayarlı breys) } \\
\text { - Takipte redüksiyon kaybı ya da ekstansör mekanizma da bozulma olursa cerrahi tedavi } \\
\text { - Deplase ise cerrahi tedavi } \\
\text { - Vida tespiti } \\
\text { - Osteoporotik kemikte serklaj kombinasyonu } \\
\text { - Çok parçalı kırık ise sirküler serklaj kombinasyonu }\end{array}$ \\
\hline $34-C$ & $\begin{array}{l}\text { - Intra-artriküler kırıklar } \\
\text { - Transvers kırıklar } \\
\text { - Çok parçalı kırıklar }\end{array}$ & $\begin{array}{l}\text { - Cerrahi tedavi } \\
\text { - K-teli ile Gergi bandı tekniği } \\
\text { - Vida ve K-teli kombine gergi bandı tekniği } \\
\text { - Vida ve K-teli kombine gergi bandı tekniği ile birlikte sirküler serklaj uygulaması } \\
\text { - Parsiyel veya total patellektomi }\end{array}$ \\
\hline
\end{tabular}




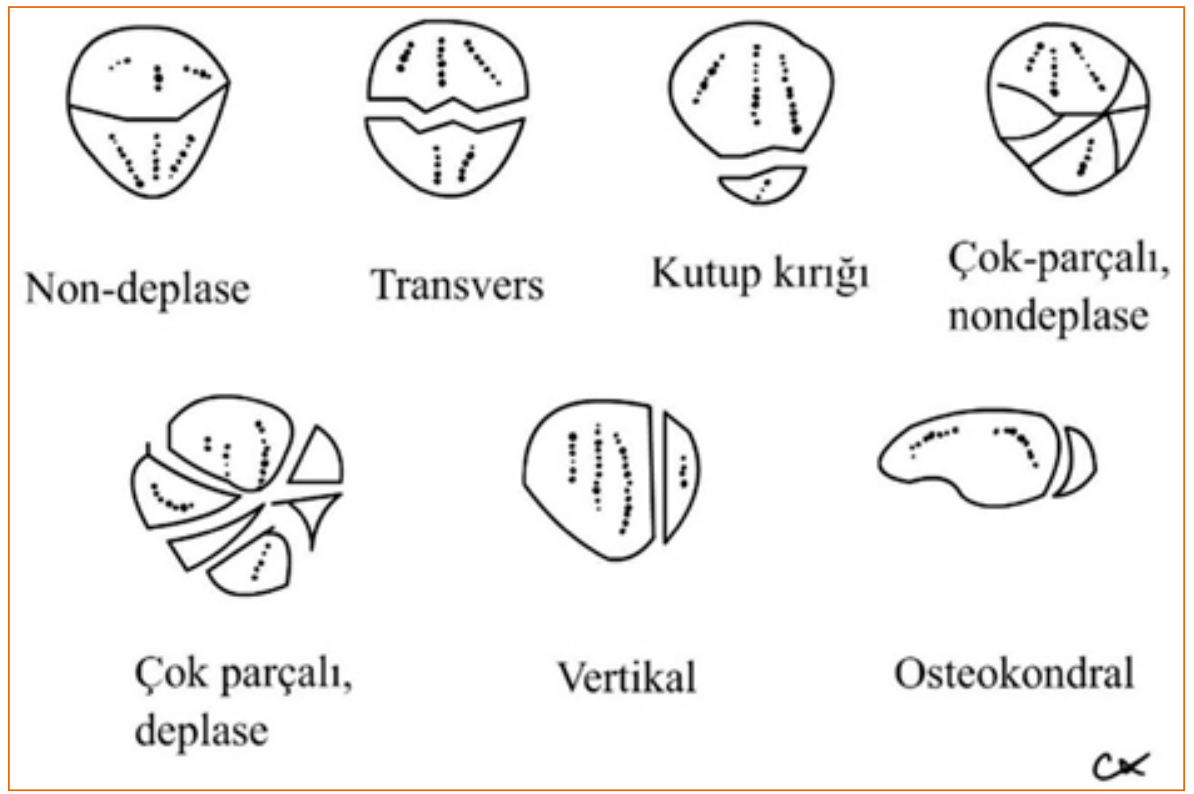

Şekil 1. Kırığın geometrik şekli, deplasman miktarı ve yerleşimini tanımlayıcı sınıflama.

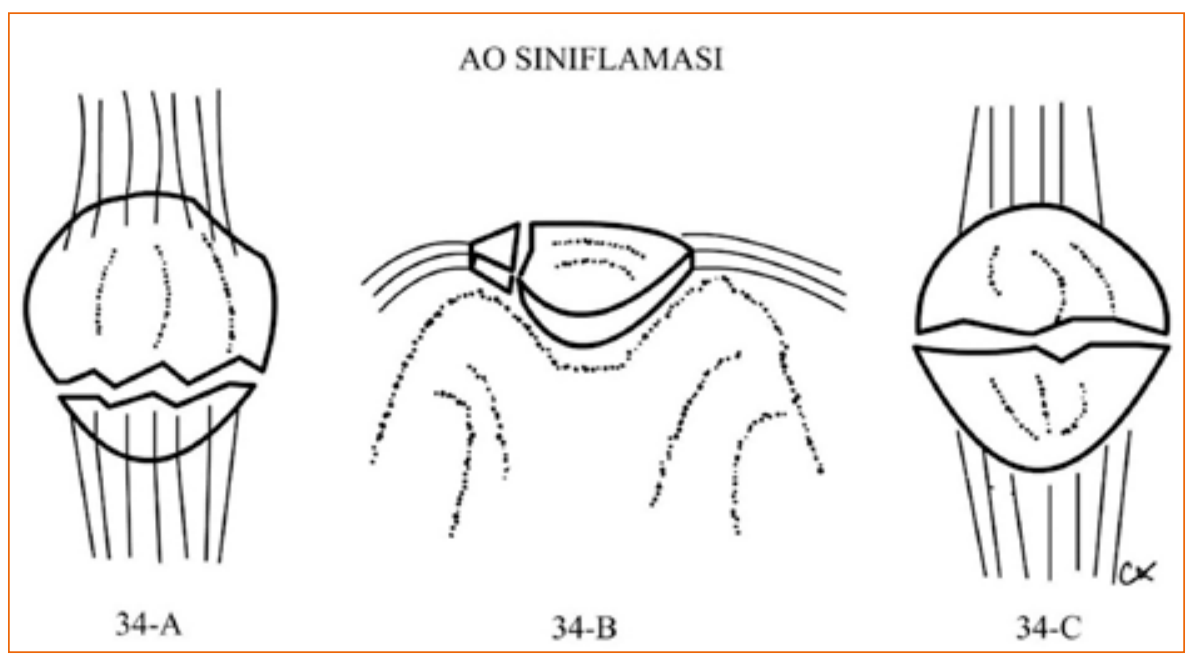

Şekil 2. AO/OTA kırık sınıflaması.

hafta ekstansiyonda tespit (kilitli açı ayarlı breys veya sirküler alçı) şeklinde yapılır. Tedavinin en geç 1 . haftasında kuadriseps atrofisine engel olmak amacıyla düz bacak kaldırma gibi izometrik kuadriseps egzersizlerine başlanır. Diz ekstansiyonda olacak şekilde koltuk değneği yardımı ile yük verilebilir. İki haftalık aralıklarla düzenli radyografik kontroller yapılır ve deplasman saptanırsa cerrahi tedavi açısından değerlendirilir. Grafide kallus oluşumu izlendikten sonra kontrollü diz fleksiyonuna başlanılır. ${ }^{[1]}$ Tam iyileşme 8-10 hafta civarındadır. Ayrıca, cerrahiye engel olacak ek hastalığı bulunan veya genel durumu kötü olan hastalarda konservatif tedavi uygulamak gerekebilir. ${ }^{[6]}$
Patella kırıklarında başlıca cerrahi endikasyonlar ${ }^{[1,7]}$;

- Parçalar arasında 3 mm'den fazla deplasman ya da 2 mm'den fazla eklem deplasmanı veya eklem içi basamak

- Tüm ekstansör mekanizma yaralanmaları

- Deplase olmuş veya serbest eklem içine düşmüş osteokondral kırıklar

- Açık kırıklar

- Kompartman sendromunun eşlik ettiği patella kırıkları 
Açık patella kırıklarında cerrahi tedavi acildir. Illk 6-8 saat içinde cerrahi tedavi yapılmalıdır. Eklem içi debridman ve stabil tespit yapılmalıdır. Tekrarlayan debridman ve yara kapama problemleri gelişebilir. Tedavide uygun antibiyotik seçimi şarttır. ${ }^{[1,7]}$

Cerrahi tedavide supin pozisyon ve radyolusen masa tercih edilir. Opere edilecek taraftaki kalçanın altına yükseklik konulur. Turnike sarılırken diz $90^{\circ}$ 'den fazla fleksiyona alınarak ve kırı̆ıın proksimal parça elle olabildiğince distale itilerek şişirilmelidir. Bazı olgularda redüksiyon sırasında turnikeyi söndürmek gerekebilir.

Cilt insizyonunda sıklıkla longitudinal insizyon tercih edilir. Longitudinal insizyonun proksimal ve distale uzatılabilmesi ve geç dönem revizyonlarda avantajları bulunmaktadır. Transvers insizyonun kozmetik sonucu daha iyidir, bu insizyonda safenöz sinirin infrapatellar dalına dikkat etmek gerekir.

Sıklıkla kullanılan K-teli ve gergi bandı tekniği; diz fleksiyonu ile oluşan gerilim kuvvetlerini kompresif kuvvetlere çeviren aktif bir sistemdir. Tespit 1,6-2,0 mm'lik K-telleri ve 1,0-1,25 mm serklaj teli ile yapılır. Öncelikle K-teli dıştan-içe veya içten-dışa teknik ile geçilir, sonrasında serklaj teli sekiz şeklinde kemik üzerindeki seyri boyunca olabildiğince kemiğe yakın olacak şekilde yerleştirilir. Sıfır şeklindeki serklaj teli bükülme kuvvetlerine daha çok dayanıklı olsa da, K-telleri ve patella etrafından retinakulumu sıyırıp posteriora geçebilir ve tespitin gergi bandı özelliği kaybolur. Bu nedenle, öncelikle sekiz şeklinde serklaj sarılması önerilmektedir. Çok parçalı kırıklarda bu tespitlere ilave olarak serklaj teli ya da örgülü sütür sirküler uygulanabilir.

Vida tespitinde; patellar kemiğin yüksek dansitesi nedeniyle çektirme vidası yerleştirilmesi sırasında vidaya yüksek tork uygulanabileceği ve redüksiyon kaybı olabileceği bilinmelidir. Vida uygulama yöntemleri ve kombine teknikler;

- İzole interfragmanter vida tespiti,

- K-teli ve gergi bandı tekniğine ek olarak serbest interfragmanter vida tespiti,

- Transvers patella kırıklarında kanüllü vida tespiti ve bu vidaların içinden serklaj teli geçirilerek sekiz şeklinde veya dikdörtgen şeklinde gergi bandı uygulanması ile birlikte tespit ve

- Bu tekniklere ek olarak ilave sirküler serklaj veya sütür uygulanmasıdır.

Artroskopi eşliğinde uygulanan minimal invasif ve perkütan tespit yöntemleri de tanımlanmıştır. ${ }^{[8]}$
Ciddi deplasmanı bulunmayan olgularda minimal invaziv olarak tespit sağlanabilir. Patella kırıklarında plak ve vida tespiti nadirdir. Özellikle çok parçalı ya da kaynamama tedavisinde plak uygulanabilir. ${ }^{[9]}$ Osteokondral parça bulunan kırıklarda başsız vida ile tespit yapılabilir.

Özellikle avulsiyon kırıklarında parsiyel, eklem yüzü çok parçalı patella kırıklarında total patellektomi tedavi tercihi olabilir. Patella kırıklarında mümkün olduğunca kırık parçalarının tespiti ve kemik stoğunun korunması önemlidir. Proksimal veya distal kutup kırıklarında tespit sağlanamıyorsa kısmi patellektomi uygulanabilir. Krackow tekniği ile, patellar veya kuadriseps tendonuna emilmeyen sütür geçirilir ve diz hiperekstansiyonda iken patellaya tespit uygulanır. Patella inferior kutup kırıklarında patellotibial serklaj tekniği kısmi patellektomiye tercih edilebilir. ${ }^{[2]}$ Parsiyel patellektomi ise her zaman total patellektomiye tercih edilen yöntemdir.

Şiddetli parçalanma ve yaygın kartilaj hasarı varlığında ya da başarısız cerrahi girişimler sonrasında total patellektomi tercih edilmek zorunda kalınabilir. Total patellektomi sonrasında yaklaşık 3-4 cm'lik defekt primer onarılabilir, daha büyük defekt varlığında kuadriseps ters $V$ plasti ile onarım yapılmalıdır. Ayrıca, mediyal ve lateral retinakulum onarımı mutlaka yapılmalıdır. Total patellektomi sonrasında yaklaşı \% 40-50 civarında ekstansör kuvvet azalması görülür.

\section{POSTOPERATIF TAKIP}

Gergi bandı tekniği uygulanan hastalarda ameliyat sonrası dönemde alçı veya breys kullanmak çoğu kez gereksizdir. Diz eklem hareketi, dinamik gergi bandı sisteminin de kırık hattında kompresyonuna izin verir ve stabiliteyi arttırır. Ayrıca, aktif eklem hareketi kartilaj için yararlıdır. Öncelikle izometrik egzersizler ve hastanın tolere edebileceği kadar yük verme ile başlanılır. Tam yük vermeye devam eden süreçte izin verilir. Kuadriseps kas gücü yerine gelene kadar açı ayarlı dizlik kullanılabilir. Patella alt kutup kırıkları sonrasında dizlik $0-90^{\circ}$ aralığında olmalıdır. ${ }^{[2]}$

Uygulanan implantların çıkartma ihtiyacı çoğu olguda gereklidir. İmplant çıkarılması için önerilen en erken dönem ameliyat sonrası 9-12 ay sonrasıdır. ${ }^{[2]}$

İşe ve spora dönüş açısından değerlendirme hastanın yaptığı iş ve spor açısından farklılık gösterir. Merdiven çıkma ve çömelme gibi aktivite gerektirmeyen hafif işlerde çalışanlar, akut semptomlar geriledikten sonra, 1. hafta sonunda işe başlayabilirler. Diğer durumlarda 6-8 hafta ortalama işe başlama zamanıdır. 
Sporcularda kas atrofisini en aza indirmek için olabildiğince erken dönemde izometrik rehabilitasyon egzersizlerine başlanılmalıdır. Rehabilitasyon sırasında kuvvetli kuadriseps kas gücü gerektiren sıçrama ve ani hızlanma veya yön değişikliği gerektiren aktiviteler en son eklenir. Spora başlangıç zamanına, profesyonel bir klinisyen veya fizyoterapist tarafindan karar verilmelidir. Bu zaman, genellikle patella kırığı bulunan ekstremitenin kas gücü, etkilenmemiş ekstremitenin kas gücünün \%80-90'ına ulaştığı zamandır.

\section{PATELLA KIRIKLARI SONRASI GÖRÜLEN KOMPLIKASYONLAR}

Cerrahi ve konservatif takip sonrası görülen komplikasyonlar şu şekildedir:

- Diz eklem hareket açıklında azalma (hem fleksiyon kısıtlılığı hem de tam ekstansiyon kısıtlılığı önemlidir).

- Diz ekstansör kurvet zayıflı̆̆ı.

- Kuadriseps atrofisi.

- Diz önü ağrısı.

- Redüksiyon kaybı.

- Kaynamama.

- Osteonekroz.

- Enfeksiyon.

\section{PEDIATRIK PATELLA KIRIKLARI}

Avulsiyon kırıkları pediatrik olgularda sıktır. Standart radyografilerde tanı zordur. Ayrıca, radyografide tanı konan avulse parça büyük ölçüde kıkırdaktan oluştuğu için görüldüğünden daha büyüktür. Avulsiyon kırıklarının tedavisi kuadriseps veya patellar tendon yaralanmaları ile benzerdir ve genellikle cerrahi tedavi gerektirir. Tanıda mutlaka karşılaştırmalı radyografi çekilmelidir. Ayırıcı tanıda, çocuklarda sık olan patellar subluksasyon ve dislokasyonlar, radyografik ayırıc tanıda bipartit patella ve apofizit (Sinding-Larsen-Johansson sendromu) açısından dikkatli olunmalıdır.
SONUÇ

- Patella kırıkları direkt künt travma ya da indirekt travma sonucu oluşur.

- Bu kırıklarda aktif diz ekstansör mekanizmasının (bacağın yer çekimine karşı uzatma kabiliyeti) değerlendirilmesi ve açık kırık varlığının muayenesi büyük önem taşımaktadır.

- Tanıda genellikle standart radyografiler yeterli olur. Lateral diz radyografisi en önemlisidir.

- Tedavide mümkün olduğunca kemik stoğunu koruyan yöntemler tercih edilir, patellektomiden kaçınılmalıdır.

- Cerrahi endikasyonlar içindeki en önemli hususlar; $3 \mathrm{~mm}$ 'den fazla deplasman, $2 \mathrm{~mm}$ 'den fazla eklem deplasmanı veya eklem içi basamak ve ekstansör mekanizma yaralanmalarıdır.

- Cerrahi tedavide ilk akla gelen K-teli ve gergi bandı uygulama yöntemidir.

- Ameliyat sonrası dönemde; izometrik egzersizler, erken hareket ve aktif diz eklem hareket açıklığı kazanılması önemlidir.

- İmplant çıkarma, ameliyat sonrası 9-12 ay sonrasında önerilmektedir.

\section{KAYNAKLAR}

1. Rockwood CA, Green DP, Bucholz RW. Rockwood and Green's fractures in adults. Philadelphia: Wolters Kluwer Health/Lippincott Williams \& Wilkins; 2010.

2. Thomas P Rüedi, Richard E, Buckley CGM. AO Principles of Fracture Management, 2nd ed. Germany: Thieme Medical Publishers; 2007.

3. Zabierek S, Zabierek J, Kwapisz A, Domzalski ME. Bipartite Patella in 35-Year-Old Fitness Instructor: A Case Report. Int J Sports Phys Ther 2016;11(5):777-83.

4. Oohashi $Y$, Koshino T, Oohashi Y. Clinical features and classification of bipartite or tripartite patella. Knee Surgery, Sport Traumatol Arthrosc 2010;18(11):1465-9. Crossref

5. Scolaro J, Bernstein J, Ahn J. In Brief: Patellar Fractures. Clin Orthop Relat Res 2011;469(4):1213-5. Crossref

6. Pritchett JW. Nonoperative treatment of widely displaced patella fractures. Am J Knee Surg 1997;10(3):145-8.

7. Melvin JS, Mehta S. Patellar fractures in adults. J Am Acad Orthop Surg 2011;19(4):198-207. Crossref

8. Schuett DJ, Hake ME, Mauffrey C, Hammerberg EM, Stahel PF, Hak DJ. Current Treatment Strategies for Patella Fractures. Orthopedics 2015;38(6):377-84. Crossref

9. Taylor BC, Mehta S, Castaneda J, French BG, Blanchard C. Plating of Patella Fractures. J Orthop Trauma 2014;28(9):e231-5. Crossref 